\title{
Design of a new Type of Artificial Reef
}

\author{
Shaojie Jiang, Wei Wu \& Linglong Zong \\ School of Shanghai Ocean University, Shanghai 201306, China
}

\begin{abstract}
Because of over fishing and environmental pollution, global fisheries resources is declined shapely, many natural fisheries were severely damaged. At present, marine ranching construction has been developed rapidly in the coastal countries, and has obtained the good effect. Artificial fish reef is the main means of repairing marine ranching. This paper designs a new type of artificial reef. It combines solar power generation technology with artificial reef. Solar energy has provided energy for the reef body lamp. At the same time, submarine shooting device was also designed, which can observe the gathering fish effect on artificial reef all the time. The submarine shooting device also can obtain information and gathering information timely, and provide a basis for the future research.
\end{abstract}

KEYWORD: Artificial reef, Solar energy, Attractive effects

\section{INTRODUCTION}

As the world population is serious increasingly, the grain problem is put in more and more important position. Land farming and animal husbandry has not been satisfied with people's demand for food and protein gradually, so people look into the sea, the cradle of life. With the rapid development of world fishing, rich protein of high quality is provided, which greatly eased the contradiction between human and natural ecological system and caused tremendous pressure to ocean. For our country, the traditional marine fishing industry is still in the extensive stage of development. Starting in the 1970s, sustained and rapid development of fishery makes fishery resources of Chinese offshore decline year by year, led to a series of problems, such as the decrease of breeding quality and environment problem [1], etc. For this reason, some fisheries developed countries and regions began construction of the oceanic ranch. Fishery system, as a new type of sustainable aquaculture sea ranch has been confirmed by Japan and other countries can achieve good effect [2]. Artificial reef is an important part of marine pasture construction, it can repair and optimize the marine biological games live or habitats, and to repair and optimize the water ecological environment.

Generally, reefs is designed mainly from the aspects of water dynamics, biology and material science[3]. Fish lamp whose energy comes from solar battery are combined with artificial reefs, which is a passive way in collecting fish, while light induction is an active way which can set fish together. It has better effect to lure the fish. Submarine shooting device can not only observe the gathering fish effect on artificial reef all the time but also obtain and gather information timely, which will provide a basis for the future research. At the same time the overall structure is simple, practical, easily to operate.

\section{OVERALL DESIGN}

This new type of artificial reefs consists of floating plate, solar power systems, spreader, submarine shooting device and reef body while the solar power system consist of the solar energy battery and waterproof boxes. The spreader is divided into three parts, containing cable wire rope of nylon rope, fish reef wire rope and supporting bar, as shown in figure 1. 


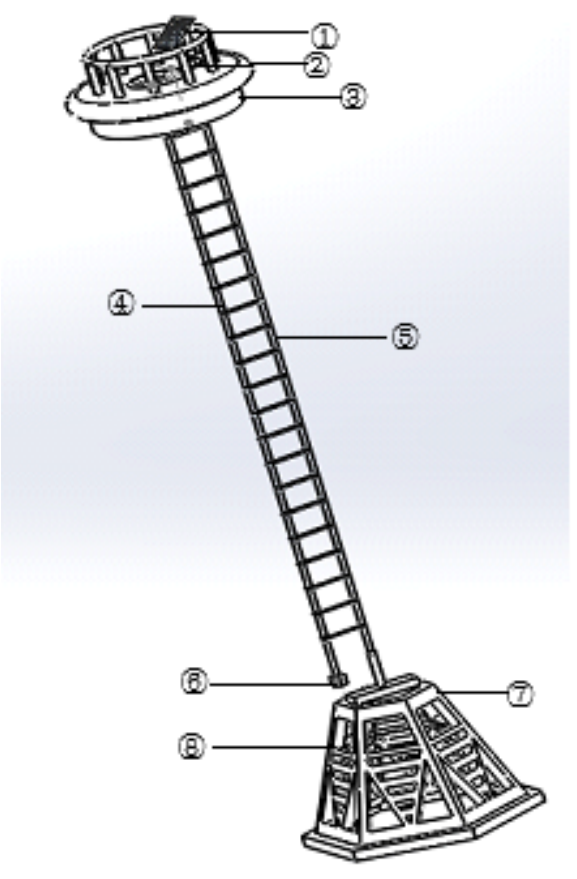

Figure. 1 The overall design of artificial reefs 1-solar cell module 2-waterproof box 3-Floating plate 4nylon cord 5-Reefs wire rope 6-Wireless panoramic camera 7-The reef body 8-LED lamp

\section{THE STRUCTURAL DESIGN OF THE KEY COMPONENTS}

\subsection{The design of the floating plate.}

Floating plate shown in figure 2 is hollow. The shape is like a flying saucer, about $50 \mathrm{~kg}$ weight, with $1.5 \mathrm{~m}$ upper radius. The bottom of it is a cylinder with $1.2 \mathrm{~m}$ radius and $0.8 \mathrm{~m}$ height. The top is the shape of a hemisphere. On the top there is a handle which can be opened manually. Considering the power generation device of artificial reefs may go wrong with time going longer, it need to be repaired and maintained. Conveniently, a fence and a channel with top hole in the artificial reef floating plate are specially set up to ensure the safety of maintenance person aganist slipping into the water accidently. This design is convenient and reliable.

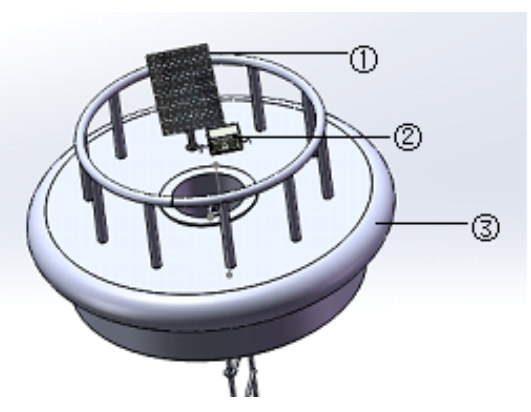

Figure. 2 The floating plate

Floating plate can bear $280 \mathrm{~kg}$, including the weights of three adults, solar panels and its fixing device, floating plate.

$$
\begin{aligned}
& F_{\text {flotage }}=\rho g v=1025 \times 9.8 \times \pi \times 1.2^{2} \times 0.8=36336 N \\
& G=m g=(225+5+50) \times 9.8=2744 N \\
& F_{\text {join }}=F_{\text {flotage }}-G=36336-2744=33592 N>0
\end{aligned}
$$

So floating plate won't sink.

\subsection{The design of solar power systems.}

Solar panels device is shown in figure 2 , the wire is directly under solar panels (1), while solar controller and battery is installed in the waterproof box(3) of the floating tray. Solar battery array receive solar radiation and convert them into voltage. Through a solar controller, the input voltage after effective output for fixed voltage, deposited in the battery, can supply the underwater reef fish body directly.

Because single crystal silicon solar cells have high conversion efficiency [4] and can absorb a certain amount of strong winds and snow load without easily to be damaged, $50 \mathrm{~W}$ single crystal solar panels, with size $350 * 800 * 30 \mathrm{~mm}$ and weight $3.8 \mathrm{~kg}$ is chosen.

\subsection{The design of the spreader and submarine shooting device.}

The spreader (Fig 3) is composed of nylon rope(4) mixed with cable, wire rope and crossed supporting bar. A hook connected with the hook seat placed on the inner wall of the float disc passage hole is arranged at the upper end of the fish reef steel wire rope. The right end of the supporting rod is a horizontal hook connecting with fish reef steel wire rope. The left end of the supporting rod is connected with the nylon rope mixed with cable.

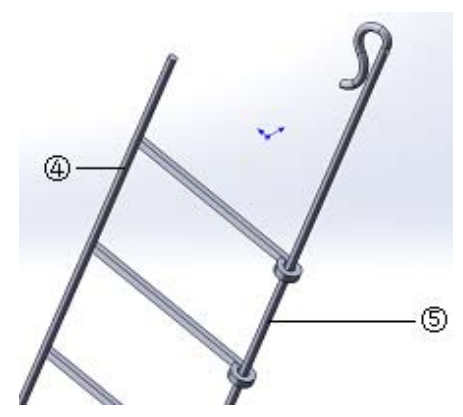

Figure. 3 The sling

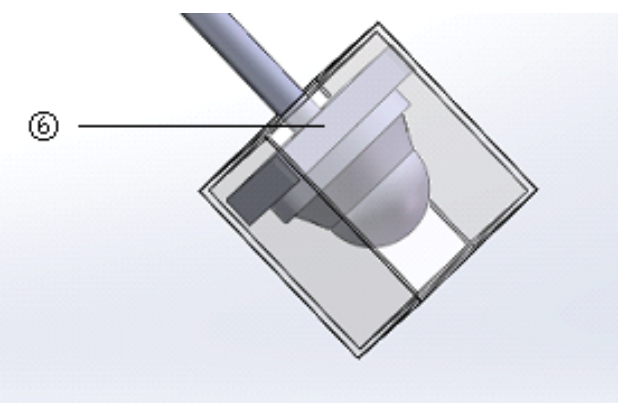

Figure. 4 Submarine shooting device 
A waterproof glass box is arranged at the end of the lower end of the cable nylon rope. There a wireless panoramic camera inside. The input terminal of camera power is connected with the waterproof glass box cable. Underwater shooting device can obtain underwater photos in real time. It's convenient for staff to collect information, observe the fish effect of artificial reef.

In addition, due to waterproof glass box immersed in the bottom of the sea in a long time, it may be covered with algae in the surface of waterproof glass box and the camera lens. It is necessary to clean up the underwater waterproof glass box by spreader with infinite length, good toughness and easy to use, Especially the support bar can prevent electric cable contains a nylon rope and reef fish wire rope from winding and knotting, Maintenance personnel just need board the floating disc, pull the nylon rope, take off the steel wire rope from under transverse hook, and then pull the waterproof box out of the bottom, wipe and clean the glass surface. It will greatly eliminate the time and energy of maintenance.

\subsection{The design of the reef body.}

Artificial fish reef $(0.8 \times 2 \times 2.4 \mathrm{~m})$ shown in Figure 5 is a polyhedral prism frame. This kind of artificial reefs are easy to be produced, and each face has a large through hole, which is easy for fish to be in and out of the reef, and each face is provided with an inverted triangle structure, resulting in reef fish produce partial shadow to form a good environment for fish to live in. The body of fish reef is also provided with an LED lamp belt which is electrically connected with the solar power generation device, and can adjust the light intensity of the fish attraction in the natural sea area so that the fish can be gathered more quickly.

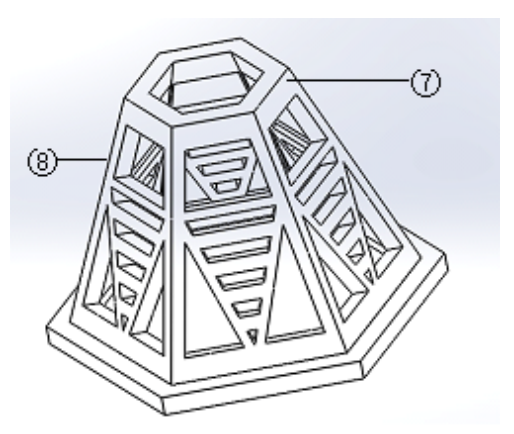

Figure. 5 The reef body

\section{CONCLUSION}

The rational setting of artificial reef can improve ecological environment of marine and create a good inhabit environment for marine creatures. It plays an important role in our country's increasingly declined fishery resources and the destruction of the marine environment. Fish-gathering effect is an important factor of reef in evaluation of design. This design uses the underwater filming device for collecting information and analyzes the reefs practicability. The new artificial reef is suitable in the shallow coastal areas, and we can get underwater images on the floating plate at any time. It can eliminate the inconvenient disadvantage of underwater observation, and is easier for staff to collect information and observe attractive effect of artificial reef. Also by gathering information, it is convenient for designing and improving the subsequent reefs. The artificial reef can provide a good living environment for marine life, and information collection is also advantageous for further exploring. We should work harder to create a good marine environment.

\section{ACKNOWLEDGEMENTS}

This work was financially supported by Solar Energy Artificial Reef Programs of Innovation for Undergraduates.

\section{REFERENCES}

[1] Zhang Fusui. Review and Prospect of the development of modern Chinese aquaculture industry [J]. World Science and Technology Research and Development, 2003, 25 (3):5-13.

[2] Xuan Yetai, Long Tanaka Takehiro, Lin Haozhi. Composite type marine ranching log off and mount in fish stocking in Japanese set a status and fish [J]. Fisheries Engineering, 1999, 35 (3): 303-309.

[3] Tao Feng, Jia Xiaoping, Chen Pimao, et al. Research progress on the design of artificial reefs in the South [J]. Fisheries in South, 2008, 4 (3): 64-69.

[4] Xu Weimin, Zhao Hongbing, Feng Qiuhong. Principles and types of solar cells [J]. Power Generation Equipment, 2011, 02:137-140. 